\title{
Evaluation of Neutron Imaging for Measuring Phosphoric Acid Distribution in High Temperature PEFCs
}

\author{
P. Boillat, ${ }^{\mathrm{a}, \mathrm{b}, \mathrm{z}}$ J. Biesdorf, ${ }^{\mathrm{a}}$ P. Oberholzer, ${ }^{\mathrm{a}}$ A. Kaestner, ${ }^{\mathrm{b}}$ and T. J. Schmidt ${ }^{\mathrm{a}, *}$ \\ ${ }^{a}$ Electrochemistry Laboratory (LEC), Paul Scherrer Institut (PSI), 5232 Villigen, Switzerland \\ ${ }^{b}$ Neutron Imaging and Activation Group (NIAG), Paul Scherrer Institut (PSI), 5232 Villigen, Switzerland
}

\begin{abstract}
The possibility of using neutron imaging for non-invasive investigation of the phosphoric acid distribution in high temperature polymer electrolyte fuel cells (HT-PEFC) was explored with a small scale test cell. In particular, the issue of providing a suitable reference - necessary for distinguishing the neutron attenuation due to the acid from the attenuation due to the structural components - was solved by using in situ deuteration/protonation of the phosphoric acid, a fully reversible process. Experiments with a nonoperating cell have shown that this isotope exchange can be performed in less than 20 minutes. The possibility of imaging the acid distribution either over the cell area (through-plane imaging) or across the cell structure (in-plane imaging) was demonstrated. Although some discrepancies between the two modes remain, quantitative analysis resulted in a good agreement with the amount of acid used in the cell.

(C) The Author(s) 2014. Published by ECS. This is an open access article distributed under the terms of the Creative Commons Attribution 4.0 License (CC BY, http://creativecommons.org/licenses/by/4.0/), which permits unrestricted reuse of the work in any medium, provided the original work is properly cited. [DOI: 10.1149/2.023403jes] All rights reserved.
\end{abstract}

Manuscript submitted October 30, 2013; revised manuscript received December 4, 2013. Published December 14, 2013.

The durability of high temperature polymer electrolyte fuel cells (HT-PEFCs) based on phosphoric acid/polymer composites or gels is limited by several processes, mainly found in the degradation of the membrane electrodes assemblies (MEAs) and their components. Membrane thinning and pinhole formation, evaporation of phosphoric acid (both from membrane and catalyst layers), Pt dissolution and carbon corrosion from the catalyst layer have been identified as the main degradation modes. ${ }^{1}$ Although durability of several 10,000 hours have been demonstrated in laboratory environments, ${ }^{2,3}$ operation under realistic conditions including high operating temperatures of up to $180^{\circ} \mathrm{C}$, temperature cycles and start/stop cycling, combined with operation on highly impure reformates produced by fuel processors ${ }^{4}$ remains challenging in order to reach the desired $>40,000$ hours required for stationary combined heat and power (CHP) HT fuel cell systems. One of the most important, but widely underestimated and least understood topics in the development of HT-PEFCs is the behavior of the phosphoric acid electrolyte during operation. ${ }^{5} \mathrm{~A}$ detailed picture of the initial acid distribution, its re-distribution and evaporation upon fuel cell operation is missing, although it is one of the key points to be addressed when it comes to the design of highly durable MEAs and cells for HT-PEFCs. Recently, the deleterious effect of acid movement from MEA into the pores of bipolar plates on the durability of HT-PEFC MEAs ${ }^{6}$ could be demonstrated. In this study, only cells with completely non-porous plate materials suppressing quick acid distributions during operation showed high durability, whereas cells allowing for acid movement from MEA to plates could not be operated for much longer than $300 \mathrm{~h}$, pointing out the importance of understanding the acid transport within the cell. A possibility to measure distribution of liquid electrolyte in alkaline, phosphoric acid and molten carbonate fuel cells by using an electrochemical impedance sensor located in the bipolar plate material has been described by Kunz. ${ }^{7}$ In this work, e.g., the phosphoric acid reservoir content relative to the undisturbed ex-situ value could be measured under operation analyzing the high-frequency part of the impedance spectrum. Other attempts have been taken to understand acid (re-)distribution by disassembly of cells and cell components in PAFCs $^{8}$ and HT-PEFCs ${ }^{9}$ and further acid content analysis by acidbase titration. These ex situ results, however, may not reflect the state and distribution of acid under operation conditions and typically contain a relatively large error bar. Indirect acid content determination by electrochemical catalyst surface area analysis ${ }^{8}$ using either cyclic voltammetry or electrochemical impedance spectroscopy limits information to the catalyst layer only, but only little or no information is

*Electrochemical Society Active Member.

${ }^{\mathrm{z} E}$-mail: pierre.boillat@psi.ch available for the membranes, the gas diffusion layers and the channel regions of the plates. First real in situ attempts for the understanding of the MEA phosphoric acid distribution and re-distribution have been performed by Maier et al. ${ }^{10,11}$ using in-situ X-ray radiography. In these studies, the distribution of the acid as function of current density could be imaged in-plane, i.e., in the cross-section of the fuel cell, and membrane expansions and contractions on the micrometer scale was interpreted as a result of adapting phosphoric acid concentration as function of water partial pressure. Recently, first 3D X-ray tomographic microscopy images of HT MEAs have been recorded at PSI and successfully segmented for quantitative determination of the phosphoric acid content and concentration in the gas-diffusion layers of HT-PEFC MEAs. ${ }^{12}$ However, the necessity of having a structure transparent to X-rays sets strong constraints on the cell design. In this context, the possibility of using neutron radiography would be highly valuable due to the high penetration of neutrons through usual fuel cell components. In this manuscript, we will demonstrate, for the first time, the potential of neutron radiography to study the distribution of phosphoric acid within HT-PEFCs. This work is focused on solving the issue of separating the attenuation due to acid from the attenuation due to the structural components. For this purpose, we make use of isotope exchange between ${ }^{1} \mathrm{H}$ (protium) and ${ }^{2} \mathrm{H}$ (deuterium, D) in order to achieve correct referencing, a technique we recently could successfully apply for the study of water transport properties of low temperature PEFCs. ${ }^{13,14}$

\section{Theory}

Characteristics of neutron imaging.- Neutron imaging has the advantage of providing a high contrast for hydrogenated compounds, as well as a good penetration for fuel cell construction materials (e.g. aluminum, graphite, stainless steel). Many studies (e.g. ${ }^{15-24}$ ) have taken advantage of these unique characteristics for imaging liquid water in low temperature polymer electrolyte fuel cells (PEFCs). In the case of phosphoric acid imaging in HT-PEFCs, there is an additional issue concerning the reference image. Despite the fact that the structural materials are transparent enough to neutrons, they induce some attenuation of the beam. To distinguish the attenuation caused by the structure from the attenuation caused by the species to be measured, a reference image including only the structure is necessary. ${ }^{15}$ For the imaging of water, this is simply done by drying the cell before or after the experiments. In the case of HT-PEFC, there is no easy way to remove all the phosphoric acid, and doing so would represent an irreversible degradation of the cell. To solve this issue, a further characteristic of neutron imaging can be used. The neutrons interact with the nucleus and, in many cases, this interaction depends on the specific isotope of a given element. In particular, the protium $\left({ }^{1} \mathrm{H}\right)$ and 


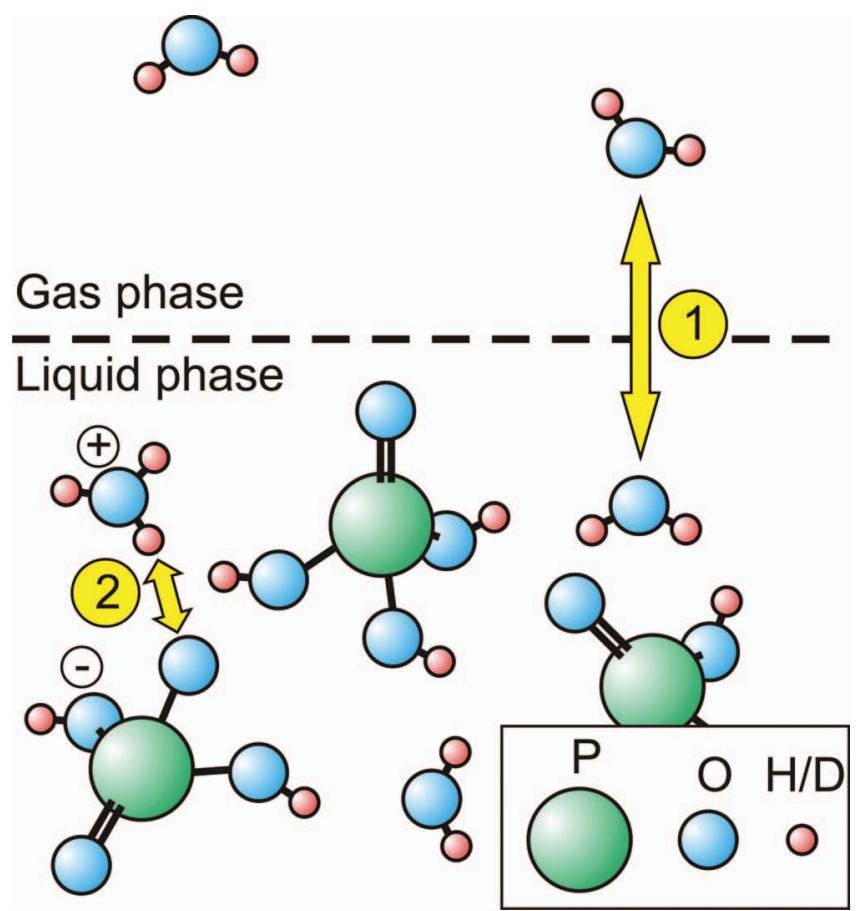

Figure 1. Illustration of the exchange processes resulting in the full deuteration of (concentrated) phosphoric acid in presence of heavy water vapor. (1) Condensation/evaporation of water. (2) Dissociation/recombination of protons.

deuterium $\left({ }^{2} \mathrm{H}\right)$ isotopes show strong differences, the neutron cross section being approximately one order of magnitude higher for ${ }^{1} \mathrm{H}$ than for ${ }^{2} \mathrm{H}$. Thus, if a given compound is deuterated (meaning that all its hydrogen atoms are exchanged with the deuterium isotopes), it becomes significantly more transparent to neutrons than the original protonated compound.

In situ deuteration of phosphoric acid.- When phosphoric acid $\left(\mathrm{H}_{3} \mathrm{PO}_{4}\right)$ is in the presence of water vapor, an equilibrium is established in which the liquid phase is composed of partly dissociated phosphoric acid and water. This dynamic equilibrium implies two different exchange processes: 1) The condensation/evaporation of water results in an exchange of water molecules between the gas phase and the liquid phase. 2) The dissociation/recombination of the phosphoric acid results in an exchange of hydrogen atoms between the $\mathrm{H}_{3} \mathrm{PO}_{4}$ (and condensates of phosphoric acid, e.g., $\mathrm{H}_{4} \mathrm{P}_{2} \mathrm{O}_{7}$ ) and $\mathrm{H}_{2} \mathrm{O}$ molecules. The exchange processes described above are illustrated in Figure 1. Concerning the second process, it must be mentioned that, even though almost no molecules have two or three dissociated protons, no specific hydrogen atom is favored. Thus, each of the atoms will be dissociated in turn and the exchange process described in point 2) concerns all three hydrogen atoms of the $\mathrm{H}_{3} \mathrm{PO}_{4}$ molecule. Due to these exchange processes, if the gas phase is constantly supplied with water vapor having a given hydrogen isotope $\left({ }^{1} \mathrm{H}\right.$ or $\left.{ }^{2} \mathrm{H}\right)$, all hydrogen atoms in the liquid phase (water and acid) will be replaced by this isotope. This allows in situ deuteration and reprotonation of the phosphoric acid (either free acid or acid bound in the membrane) by simple circulation of a gas humidified with respectively heavy water and light water.

\section{Experimental}

Cell design.- A small-scale single cell with an active area of $0.81 \mathrm{~cm}^{2}(9 \times 9 \mathrm{~mm})$ was used. The flow fields were made of gold plated aluminum with microchannels in an interdigitated configuration. HT MEAs have been formed by combining phosphoric acid doped Polybenzimidazole films (m-PBI, 2,2'-mphenylene-5,5'-bibenzimidazole, $50 \mu \mathrm{m}$ thickness, acid content/molar
Table I. Parameters of the neutron imaging setups (TP $=$ through plane, IP = in plane).

\begin{tabular}{lccc} 
Parameter & $T P$ setup & $I P$ setup & Unit \\
\hline Horiz. pixel size & 13.5 & 2.7 & $\mu \mathrm{m}$ \\
Vert. pixel size & 13.5 & 13.5 & $\mu \mathrm{m}$ \\
Horiz. effective resolution (FWHM) & 90 & 20 & $\mu \mathrm{m}$ \\
Vert. effective resolution (FWHM) & 90 & 200 & $\mu \mathrm{m}$ \\
Exposure time & 10 & 10 & $\mathrm{~s}$
\end{tabular}

ratio $\mathrm{H}_{3} \mathrm{PO}_{4}$ :PBI is approx. 5:1 resulting in approx. $10 \mathrm{mg}_{\mathrm{H} 3 \mathrm{PO} 4}$ $\mathrm{cm}^{-2}$ membrane) and two ELAT based electrodes using $0.5 \mathrm{mg} \mathrm{cm}{ }^{-2}$ $20 \% \mathrm{Pt} /$ Vulcan XC 72 in the catalyst layers (BASF Fuel Cell). The electrodes have been additionally doped with $\mathrm{H}_{3} \mathrm{PO}_{4}\left(10 \pm 3 \mathrm{mg}_{\mathrm{H} 3 \mathrm{PO} 4}\right.$ $\mathrm{cm}^{-2}$ electrode) using an in-house method which consists of defined adsorption of phosphoric acid inside the catalyst layers of electrodes floating on phosphoric acid. The cell was mounted into a temperature controlled housing made of gold plated aluminum. This housing used an electrical heating originally designed for low temperature PEFCs, which limited the maximum temperature to approximately $130^{\circ} \mathrm{C}$. Although the experiments presented here do not include the operation of the cell, the terms "anode" and "cathode" are used to describe the respective sides of the cell.

Neutron imaging setup.- Two different imaging setups were used. In through-plane configuration (membrane perpendicular to the beam axis), the distribution over the area is imaged, but no distinction can be made between the different layers. In in-plane configuration (membrane parallel to the beam axis), the distribution across the cell structure is imaged. The micro-setup for high-resolution imaging ${ }^{25}$ was used for both imaging configurations. For the through plane measurements, a ${ }^{6} \mathrm{LiF}$ based scintillator screen perpendicular to the beam was used. For the in-plane measurements, the specific anisotropic enhancements described in a previous paper ${ }^{26}$ were applied to obtain a higher resolution in the direction across the membrane. These improvements included the use of a tilted scintillator screen based on gadolinium oxysulfide $\left(\mathrm{Gd}_{2} \mathrm{O}_{2} \mathrm{~S}\right)$. The parameters of both imaging setups are given in Table I. The used definition for the effective resolution is the Full Width at Half Maximum (FWHM). A readout time of approximately $4 \mathrm{~s}$ adds to the exposure time of $10 \mathrm{~s}$. As a result, the image acquisition frequency was 4-5 images/min. All measurements were realized at the ICON beam line ${ }^{27}$ at PSI.

Operating conditions.- During all experiments reported here, a gas flow (nitrogen) was circulated on the cathode side only. The anode was purged with nitrogen after which the gas flow was stopped. On the cathode side, only a limited gas flow could be drawn, possibly due to the amount of acid in the GDL. In order to avoid too much pressure changes, a constant pressure drop between the inlet and outlet was fixed, with an inlet pressure of 1.2 bar $_{\text {abs }}$ and an outlet pressure of $1.0 \mathrm{bar}_{\text {abs }}$. The resulting gas flow was in the range of 100-200 $\mathrm{nmL} / \mathrm{min}$. The operating parameters are summarized in Table II.

Sequence of experiments. - All measurements in through-plane configurations were realized first, after which the imaging setup was

\section{Table II. Operating parameters for all experiments.}

\begin{tabular}{lll} 
Parameter & Value & Unit \\
\hline Cathode gas flow & $100-200$ & $\mathrm{nmL} / \mathrm{min}$ \\
Anode gas flow & 0 & $\mathrm{nmL} / \mathrm{min}$ \\
Cathode inlet pressure & 1.2 & $\mathrm{bar}_{\text {abs }}$ \\
Cathode outlet pressure & 1.0 & $\mathrm{bar}_{\text {abs }}$ \\
Anode pressure & 1.1 & $\mathrm{bar}_{\text {abs }}$ \\
Cathode gas & $\mathrm{N}_{2}$ & - \\
Cathode dew point & $30-70$ & ${ }^{\circ} \mathrm{C}$ \\
Cell temperature & 125 & ${ }^{\circ} \mathrm{C}$
\end{tabular}


changed and experiments in in-plane configuration were performed with the same cell. Each experiment was conducted at a fixed dew point of either $30^{\circ} \mathrm{C}, 50^{\circ} \mathrm{C}$ or $70^{\circ} \mathrm{C}$. During an experiment, the isotope was changed between light water $\left(\mathrm{H}_{2} \mathrm{O}\right)$ and heavy water $\left(\mathrm{D}_{2} \mathrm{O}\right)$. The list of conducted experiments is given in Table III. Experiments 211213 were repeated a second time at the end.

\section{Processing}

Image processing. - The images were processed using a chain of operations to reduce noise (filtering) and to correct for instrument perturbations (inhomogeneous illumination, variations in beam intensity, background components). The attenuation due to acid/water was distinguished from the structural attenuation using a referencing process, ${ }^{15}$ with the cell in fully deuterated state as a reference image. The reference image was recorded at the end of all experiments for the in-plane setup. For the through-plane setup, the image of the last five minutes of the heavy water humidification step during experiment 101 (c.f. Table III) was used as a reference. False color images were produced for better visualization of the acid/water relative to the cell structure. The acid/water is displayed in green color, superimposed to the gray scale images of the structures.

Quantification.- The quantified values presented in this work are based on the following formula corresponding to the inversion of the LAMBERT-BEER law:

$$
\delta=\frac{-\ln \left(\frac{I}{I_{0}}\right)}{\Sigma}
$$

where $\delta$ is the measured thickness, $I$ is the intensity measured in the work image, $I_{0}$ is the intensity measured in the reference image and $\Sigma$ is the attenuation coefficient of the measured material. This equation does not account for beam hardening, but according to a calculation based on the experimental white beam spectrum, and on the energy dependent detector sensitivities and hydrogen cross sections, the resulting error is less than $5 \%$ for the range of optical densities $(<1.0)$ considered here. When using a deuterated compound for the reference image, the effective attenuation coefficient used is the difference of attenuation coefficients between the protonated and deuterated compounds. The value for pure $\mathrm{H}_{3} \mathrm{PO}_{4}$ was estimated to be $0.246 \mathrm{~mm}^{-1}$ for the through plane setup and $0.222 \mathrm{~mm}^{-1}$ for the in plane setup. These values are based on the experimentally determined attenuation coefficients of water for these setups, assuming that all attenuation is due to the hydrogen - a reasonable assumption when measuring the differences between protonated and deuterated compounds. The difference in attenuation coefficient between the in plane and through plane setups is related to the different neutron absorption spectra of the respective scintillator screen materials, resulting in different $e f$ fective white beam spectra. For calculating the quantity of acid, the amount of water in the system has to be evaluated. In this work, this was done by interpolating the acid concentration - water vapor pressure equilibrium relations published in Ref. 28 . The quantity of water in the system for the three dew points used is summarized in Table IV. To obtain the equivalent thickness of pure $\mathrm{H}_{3} \mathrm{PO}_{4}$, the measured thickness was corrected according to the following formula:

\section{Table III. List of experimental sequences.}

\begin{tabular}{cccc} 
Exp & Setup & Dewpoint & Sequence \\
\hline 101 & TP & $70^{\circ} \mathrm{C}$ & $20 \operatorname{min~}_{2} \mathrm{O}, 20 \operatorname{min~} \mathrm{D}_{2} \mathrm{O}, 20 \operatorname{min~}_{2} \mathrm{O}$ \\
102 & TP & $30^{\circ} \mathrm{C}$ & $10 \operatorname{min~}_{2} \mathrm{O}, 12$ hours $\mathrm{D}_{2} \mathrm{O}$ \\
201 & IP & $70^{\circ} \mathrm{C}$ & $60 \operatorname{min~}_{2} \mathrm{O}, 30 \min \mathrm{H}_{2} \mathrm{O}, 90 \operatorname{min~}_{2} \mathrm{O}$ \\
211 & IP & $70^{\circ} \mathrm{C}$ & \\
212 & IP & $50^{\circ} \mathrm{C}$ & \\
213 & IP & $30^{\circ} \mathrm{C}$ &
\end{tabular}

\begin{tabular}{ccc}
\hline $\begin{array}{l}\text { Table IV. Water uptake as a function of humidity (data } \\
\text { interpolated from Ref. 27). }\end{array}$ \\
\begin{tabular}{ccc} 
Dew point $\left[{ }^{\circ} \mathrm{C}\right]$ & Relative humidity $[\%]$ & Water uptake $\left[\mathrm{H}_{2} \mathrm{O} / \mathrm{H}_{3} \mathrm{PO}_{4}\right]$ \\
\hline 30 & $1.84 \%$ & 0.138 \\
50 & $5.35 \%$ & 0.362 \\
70 & $13.52 \%$ & 0.770
\end{tabular}
\end{tabular}

$$
\delta_{H_{3} P O_{4}}=\delta \cdot \frac{3}{3+2 \cdot \lambda}
$$

where $\lambda$ is the water uptake (number of $\mathrm{H}_{2} \mathrm{O}$ molecules per molecule of $\mathrm{H}_{3} \mathrm{PO}_{4}$ ) as listed in

Table IV. For all results indicating values in different regions (e.g. "An. GDL"), the definitions illustrated in Figure 2 are used.

Calculation of isotope fractions. - The results of transient measurements are presented as an isotope fraction. In this work, the ${ }^{1} \mathrm{H}$ isotope fraction fraction is reported, meaning a value of 0.0 for a fully deuterated compound and a value of 1.0 for a fully protonated compound. The isotope fraction $F$ is calculated according to the following

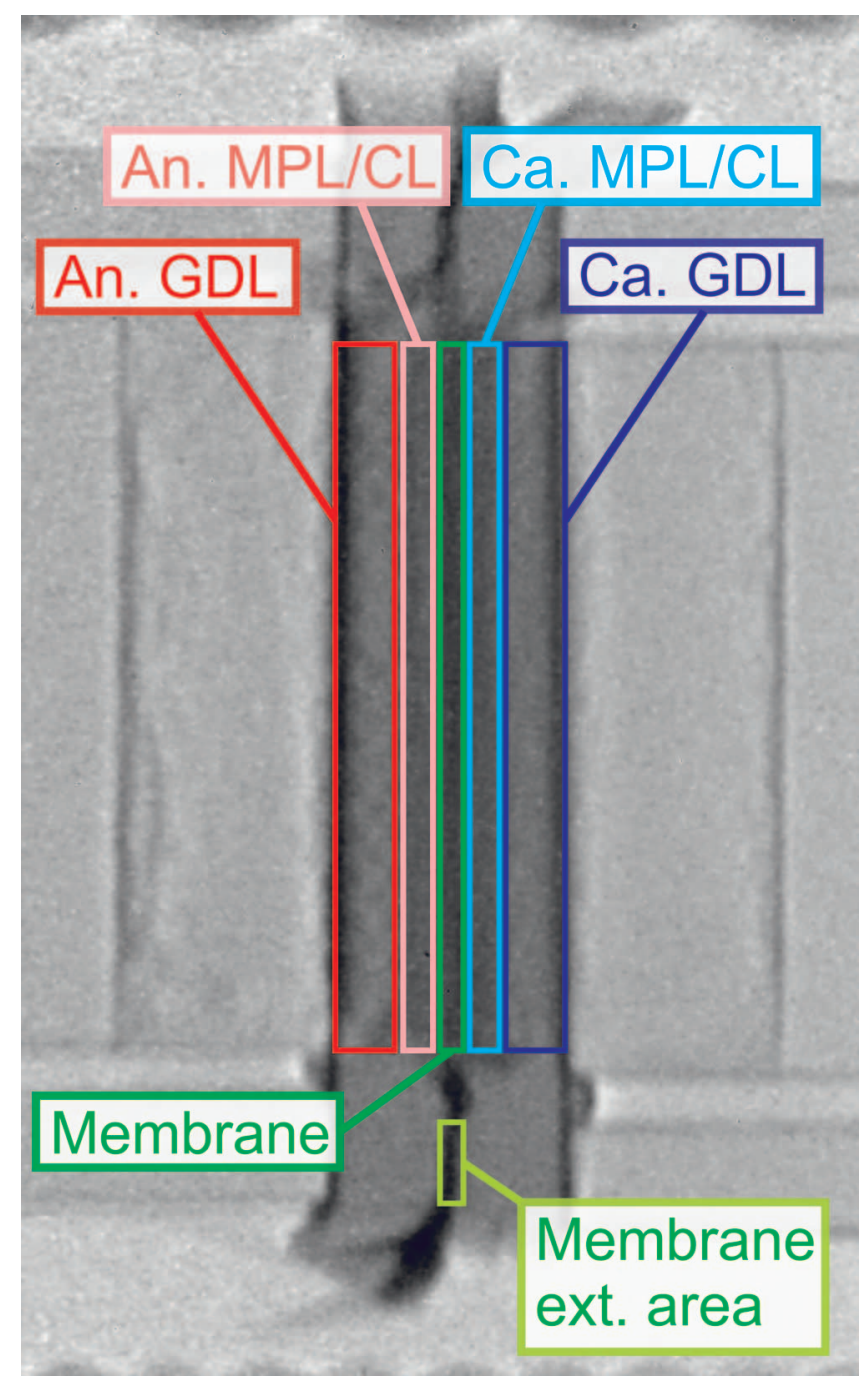

Figure 2. Definition of the averaging regions. 
equation.

$$
F=\frac{\ln \left(\frac{I}{I_{R E F, D}}\right)}{\ln \left(\frac{I_{R E F, H}}{I_{R E F, D}}\right)}
$$

Where $I$ is the intensity measured in the work image and $I_{R E F, D}$ and $I_{R E F H}$ are the intensities measured in two reference conditions. The first reference image $\left(I_{R E F, D}\right)$ is recorded in a fully deuterated state, and the second reference $\left(I_{R E F, H}\right)$ is recorded in a fully protonated state. These reference conditions are selected within the corresponding experiment. For $\exp 201$, the "fully protonated" reference is chosen within the first 10 minutes and the "fully deuterated" reference is chosen at the end of the 12 hours of heavy water operation. For exp 211-213, the "fully deuterated" reference is chosen at the end of the initial period of 60 minutes, and the "fully protonated" reference is chosen at the end of the 30 minutes period of light water humidification.

\section{Results and Discussion}

Visualization of the acid distribution in through plane and in plane configuration. - The results of the acid distribution visualization in both imaging configurations are shown in Figure 3, corresponding to experiments 101 and 211. The in-plane images shows that acid is found in both GDLs, and to some extent in the flow channels and manifolds. A repeating pattern on the anode side indicates a distribution of the acid correlated to the structure of the carbon cloth. This pattern is clearly visible on the image acquired in through-plane configuration. However, it is not directly possible to say from this image whether the acid stays preferentially between the fiber bundles or inside them, because the carbon structure does not have enough contrast for observation in through-plane images. In the in-plane image, some pattern in the anode GDL is visible as well for the image of the structure only

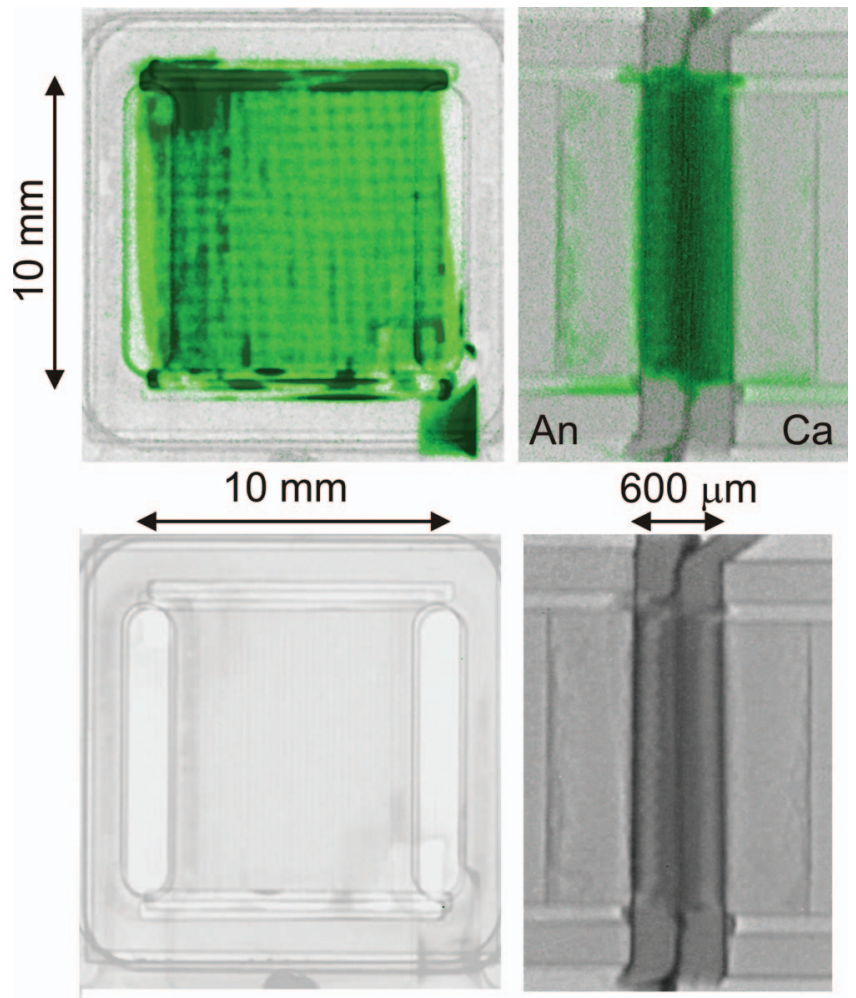

Figure 3. Visualization of the attenuation due to acid/water in through plane (left) an in plane (right) configuration. The top row shows the structure with the acid distribution overlayed in green. The bottom row shows the structure only.

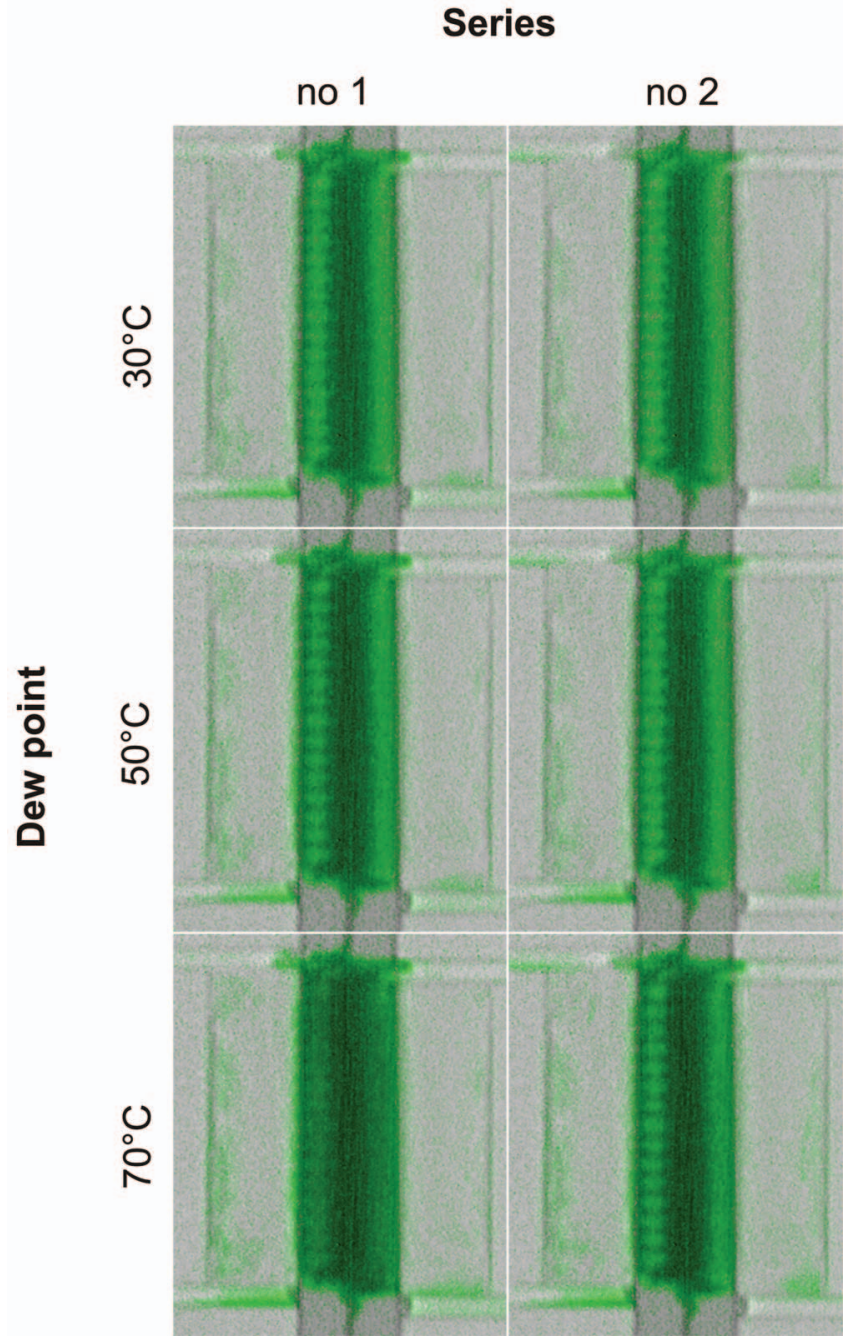

Figure 4. Distribution of acid/water at different levels of humidity (including repetition).

(bottom right image of Figure 3). However, this could come either from the carbon fiber structure or from the attenuation of the fully deuterated compound (although less than that of the protonated compound, the attenuation of deuterated acid is not zero). The in-plane images for different levels of humidity (experiments 211-213 and their repetition) are shown in Figure 4. In these figures, the total attenuation (including acid and water) is shown. The total attenuation is higher for the dew point of $70^{\circ} \mathrm{C}$, as expected from the higher water uptake by the phosphoric acid. A reduction of the acid quantity over time is also observed as a difference between the two repetitions under identical conditions - in particular between the first and second experiment at $70^{\circ} \mathrm{C}$. Apart from the previously mentioned patterned distribution on the anode side, the vertical distribution is homogeneous.

Profiles of distribution. - To further investigate the differences between the experiments, the results are plotted numerically (Figure 5) as averaged profiles across the cell structure. Based on the relations described in the "processing" section, the total attenuation is converted to an equivalent quantity of pure $\mathrm{H}_{3} \mathrm{PO}_{4}$. The corresponding optical density values - equivalent to the term $-\ln \left(I / I_{0}\right)$ in equation 1 - are also shown. In the gas diffusion layer (GDL) regions (positions from $-300 \mu \mathrm{m}$ to $-100 \mu \mathrm{m}$ and from $100 \mu \mathrm{m}$ to $300 \mu \mathrm{m}$ ), the measured distribution of acid agree reasonably well between the different conditions, with the notable exception of the first experiment at high humidity. However, the difference between this experiment 


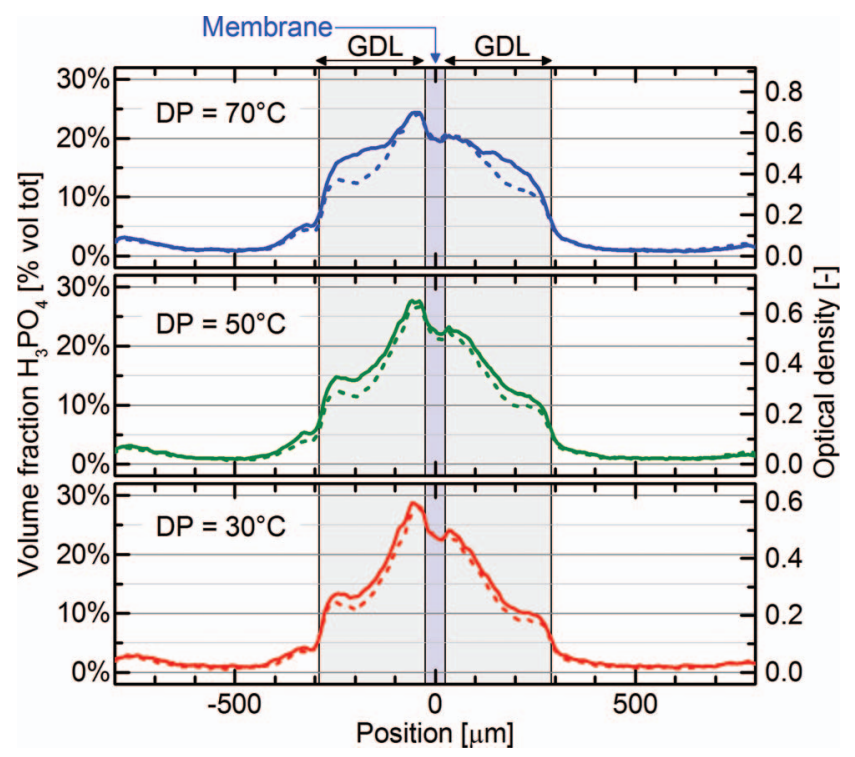

Figure 5. Profile of acid distribution across the cell structure calculated as an equivalent pure $\mathrm{H}_{3} \mathrm{PO}_{4}$ volume fraction. The corresponding optical density for each profile is shown on the right side. Dashed lines show the repetition of the experiment.

and its repetition suggests that this discrepancy is caused by a loss of acid between the experiments. In the central region corresponding to the micro-porous layers (MPL) and the membrane (positions from $-100 \mu \mathrm{m}$ to $100 \mu \mathrm{m}$ ), the measurements with dew point of $30^{\circ} \mathrm{C}$ and $50^{\circ} \mathrm{C}$ agree well, but a lower amount of acid is measured for the dew point of $70^{\circ} \mathrm{C}$. It must be reminded that the relation used to determine the water uptake corresponds to the behavior of the "free" acid. The behavior of the acid in the fine pores of the MPL (typical diameter of $0.1 \mu \mathrm{m}$ ) might deviate from this, resulting in a lower water uptake, and thus an underestimation of the acid quantity in this region. Another possible explanation to this observation is a redistribution of the acid itself as a consequence of the volume expansion with water uptake. The profiles in (Figure 5) were obtained using an individual deuterated reference for each of the experiments. The effect of using a single global reference (which is of interest for practical purposes) is further evaluated. By comparing Figure 6 a (individual references) and Figure $6 \mathrm{~b}$ (single global reference), we can see the same general distribution. However, some disturbing artifacts are added (for example, at the border of the anode GDL). Such artifacts could stem from slight structure changes over time. Nevertheless, their magnitude is relatively low compared to the measured quantity as shown by the difference profile plotted in Figure 6c.

Total quantity of acid. - The ability of neutron imaging to give quantitative information about the acid distribution is evaluated by calculating a total quantity for the cell (normalized here to the active area of the cell), as reported in Figure 7. The in-plane measurements include the flow channels and all the membrane-electrodes assembly (MEA) with the GDLs, but not the manifolds. The through plane measurements are performed on a subset of the active area with is not superposed to the manifold, and extrapolated to the entire active area $\left(0.81 \mathrm{~cm}^{2}\right)$. A clear discrepancy can be observed between the through plane measurements $\left(30-35 \mathrm{mg} / \mathrm{cm}^{2}\right)$ and the in plane measurements (20-25 mg cm $\mathrm{m}^{-2}$ ). This illustrates that some issues in quantification may remain. However, the differences may partly be due to a removal of acid in the initial phase of the experiment, and further experiments will be needed to evaluate the quantification accuracy. The target initial quantity of acid per gas diffusion electrode was $10 \pm 3 \mathrm{mg}_{\mathrm{H} 3 \mathrm{PO} 4} \mathrm{~cm}^{-2}$, representing a total quantity of $20 \mathrm{mg}_{\mathrm{H} 3 \mathrm{PO} 4} \mathrm{~cm}^{-2}$ plus the amount in the membrane. The numbers obtained here (in particular from through plane measurement) are slightly higher than expected, but within the

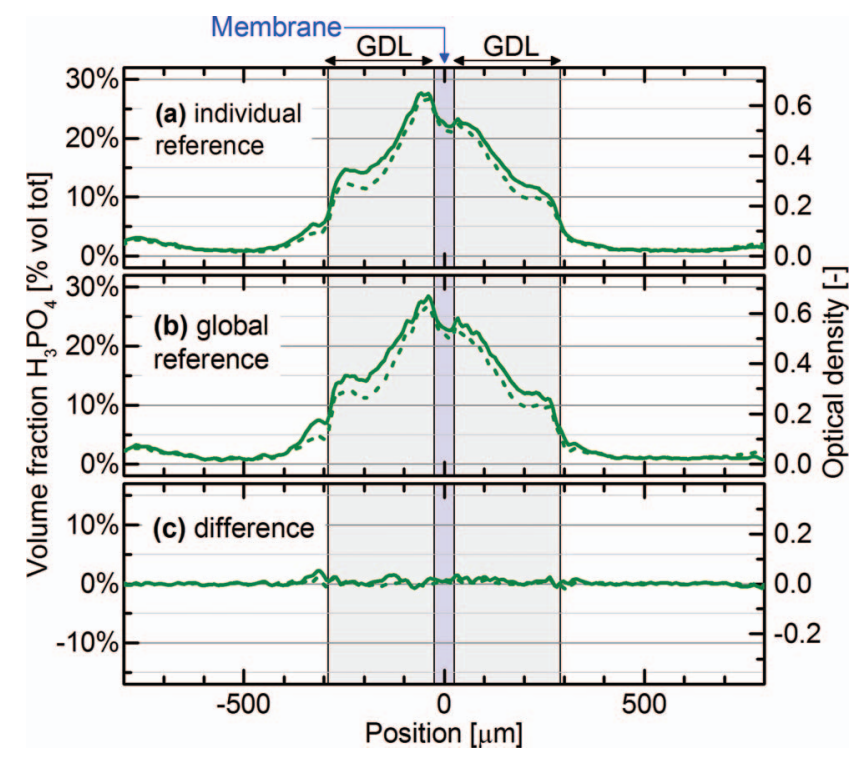

Figure 6. Effect of using (a) individual references (referencing each profile to the deuterated state during the same experiment) or (b) one single global reference. (c) Difference between the two methods. The profiles with a dew point of $50^{\circ} \mathrm{C}$ are used as an example.

range of uncertainty of the electrode doping process. In summary, the quantification results are reasonably consistent with the expected amount of acid to be found in the cell, and with the hypothesis that all hydrogen atoms are exchanged during the referencing process.

Analysis of isotope exchange transients. - The transient evolution of the isotope fraction is analyzed using in plane images, in order to distinguish the behavior in different layers of the cell. The calculation of the isotope fraction is based on the method detailed in the "processing" section. The underlying assumption is that the acid/water is fully deuterated in the first reference conditions, and fully protonated in the second reference condition. In the first experiment (201), the isotope fraction over a period of 12 hours was studied and is reported in Figure 8. As can be observed, the isotope composition in most regions is rapidly exchanged (less than 30 minutes) and remains stable during

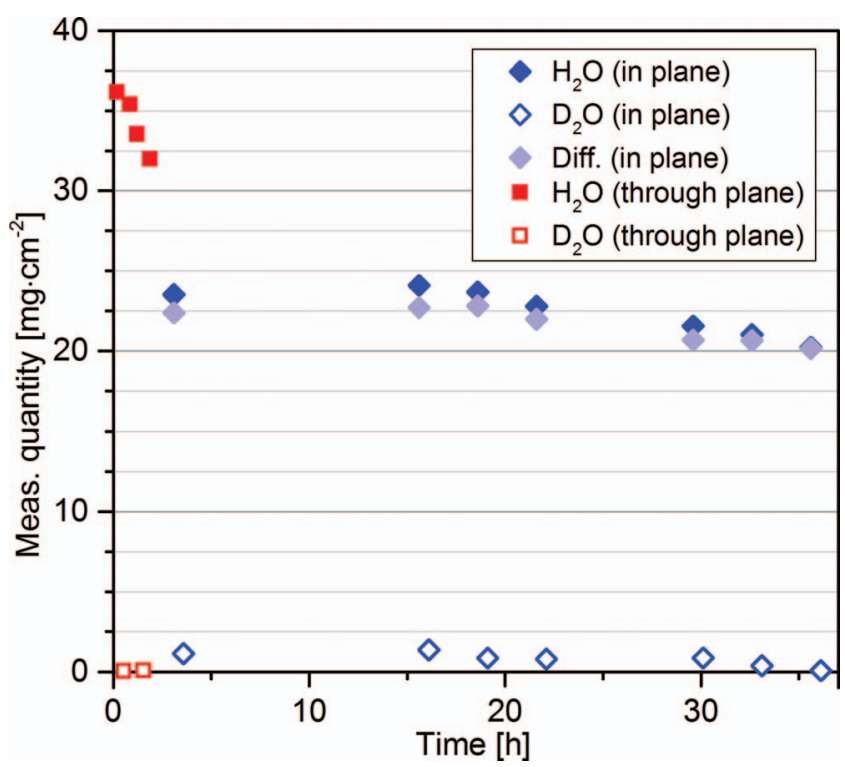

Figure 7. Total acid quantity (in $\mathrm{mg} / \mathrm{cm}^{2}$ ) measured from the through plane and in plane imaging. 


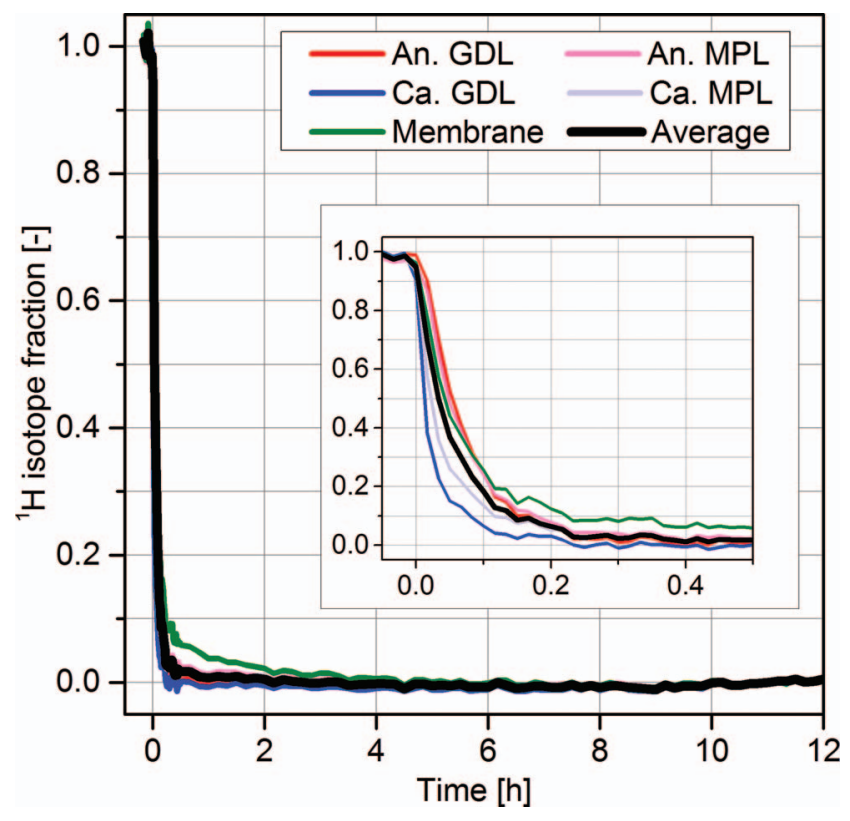

Figure 8. Evolution of the isotope fraction over a period of 12 hours (experiment 201). Insert: detail of the initial exchange.

the remaining of the 12 hours. In the membrane region, the isotope exchange occurs in two different time scales. The major part of the exchange (more than 90\%) occurs within the same time scale as for the other regions (less than 30 minutes). The remaining quantity (less than $10 \%$ ) is exchanged over a longer time scale of approximately 4 hours. Two hypotheses could be advanced to explain this behavior. Firstly, in the membrane region, a certain amount of hydrogen atoms does not belong to the acid or water, but to the PBI backbone. It could be supposed that some isotope exchange occurs on a longer time scale with these hydrogen atoms ( $\mathrm{N}-\mathrm{H}$ and $\mathrm{C}-\mathrm{H})$, although this is not very likely for $\mathrm{C}-\mathrm{H}$ bonded hydrogen atoms. A more probable explanation is given by the fact that the membrane area outside of the active area (including a section in front and behind of the active area for in plane radiograms) is not directly in contact with gases. The isotope exchange in this region relies on lateral diffusion inside the membrane. To further elucidate this hypothesis, the evolution of isotope fraction in the external membrane region in the bottom part of the cell (region illustrated in Figure 2) is plotted in Figure 9. In this region, the isotope exchange occurs over a longer period only (4-6h) which supports our second hypothesis. In summary, all isotope exchange (with the reserve of a much slower process not visible in the 12 hours time span of the experiment) occurs within the first 15-30 minutes. An exception to this is the part of the membrane situated outside the active area, which induces some perturbation in the image. In the cell used here, this perturbation remains relatively low (less than $10 \%$ ). The transient evolution of isotope fraction (cell average) for different dew points and different direction of steps is presented in Figure 10 . The exchange at lower dew points (in particular $30^{\circ} \mathrm{C}$ ) is slightly slower, but a time of approximately 20 minutes is still sufficient for full exchange. It can also be observed that the exchange is faster when switching from heavy water to light water than in the opposite direction, pointing out the possible presence of kinetic isotope effects in the exchange and/or diffusion processes.

Distribution during transients. - The distribution over the cell layers during a transient with a dew point of $70^{\circ} \mathrm{C}$ is shown in Figure 11. The corresponding temporal evolutions of isotope fraction in different regions are plotted in Figure 12. It can clearly be observed that the exchange is much faster on the cathode side, where the gas is circulated. This result identifies diffusion across the membrane (or diffusion within the acid/water in the GDL) as the major limiting process during

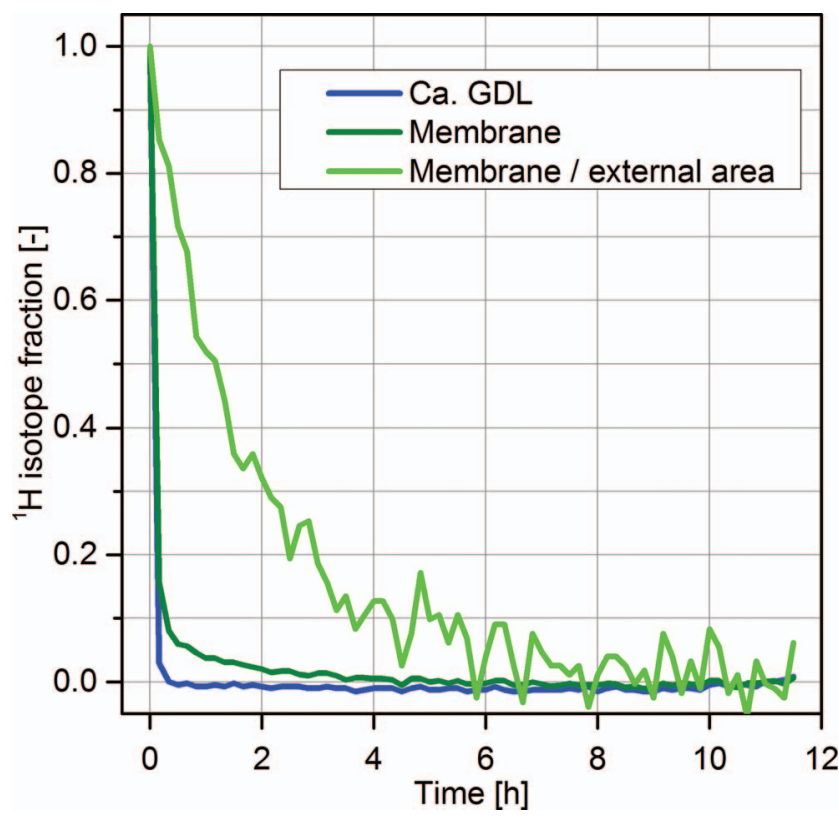

Figure 9. Evolution of the isotope fraction in the external area of the membrane.

isotope exchange. If the interfacial exchange between the gas phase and the condensed phase would have been the major limitation, a more homogeneous distribution would have been expected. This result has different practical implications. Firstly, it can be expected that the isotope exchange can be performed in a shorter time when circulating gases on both sides, making the referencing process more effective. Secondly, some information about the diffusion processes across the membrane might be obtained from isotope exchange results. Finally, the diffusion behavior could be used to distinguish the acid present in the anode and cathode sides from though plane experiments, by the comparison of experiments realized with gases circulated on the anode and cathode sides.
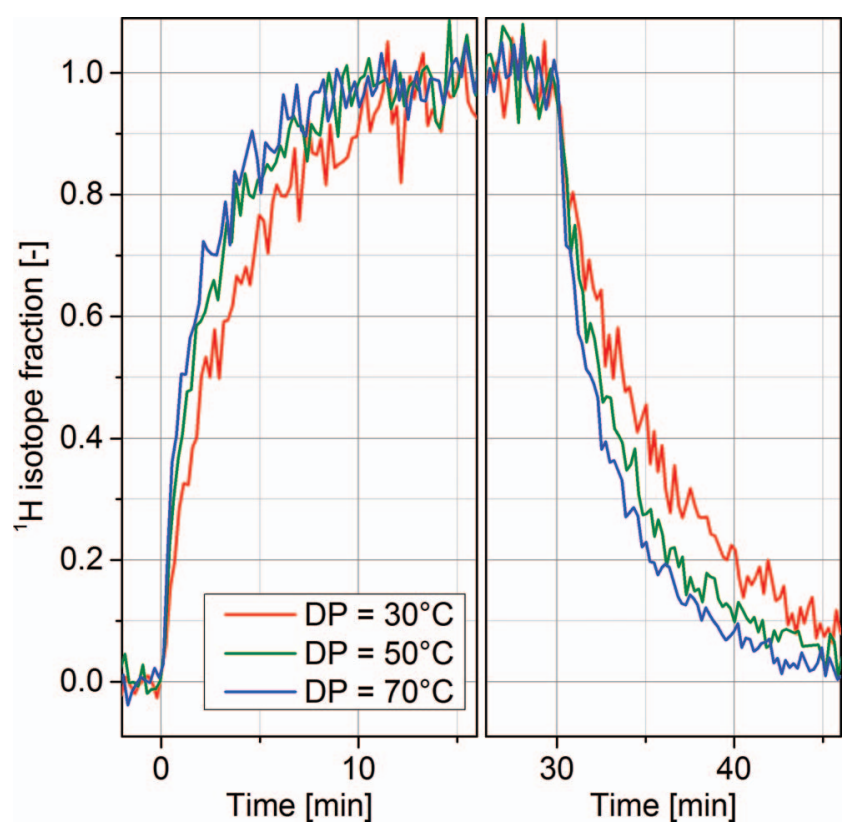

Figure 10. Transient of isotope fraction when switching from heavy water to light water (at $\mathrm{t}=0 \mathrm{~min}$ ) and vice versa (at $\mathrm{t}=30 \mathrm{~min}$ ). 


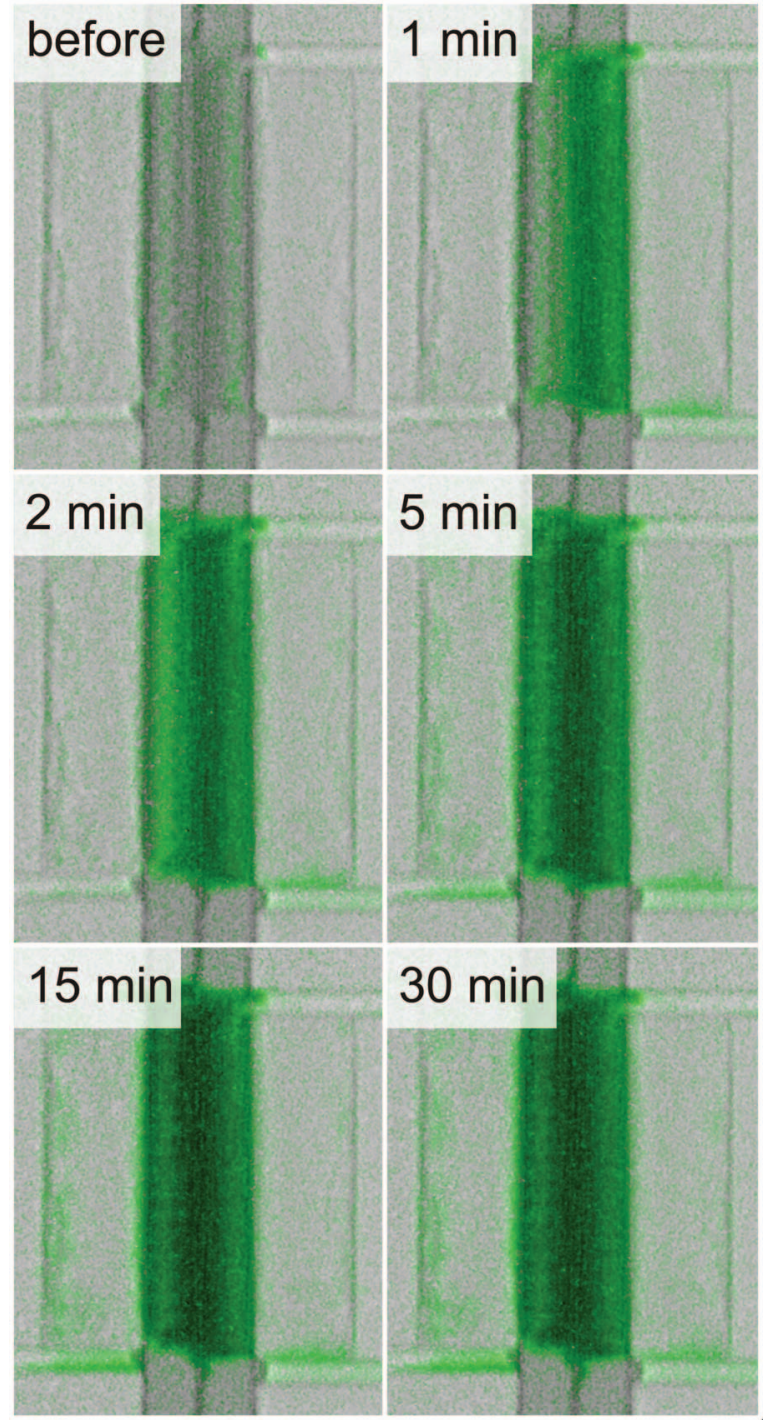

Figure 11. Distribution of acid/water over the cell structure during a transient.

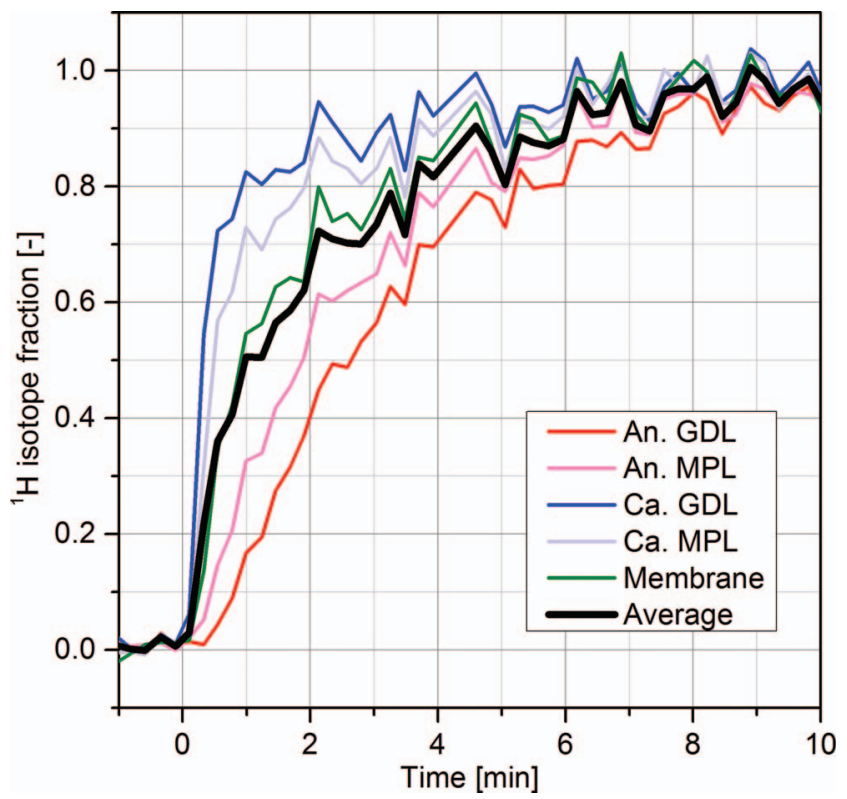

Figure 12. Evolution of isotope fraction in different regions during a transient.

\section{Conclusions}

The possibility of using neutron imaging for the analysis of phosphoric acid $\left(\mathrm{H}_{3} \mathrm{PO}_{4}\right)$ distribution in high temperature polymer electrolyte fuel cells was explored. In particular, the issue of providing a suitable reference image (including only the attenuation due to the cell structure) was solved by using reversible in-situ deuteration of the phosphoric acid. To this purpose, the dynamics of isotope exchange at different dew points between $30^{\circ} \mathrm{C}$ and $70^{\circ} \mathrm{C}$ were studied. It was observed that full deuteration can be realized in less than 20 minutes by circulating heavy water vapor on one side only. First evaluations were done concerning the ability of neutron imaging to quantify the amount of phosphoric acid. The obtained results are in quite good agreement with the expected amount of phosphoric acid in the MEA although the absolute accuracy of the determination needs some more verification. Using this method, we are now able to further study phosphoric acid distribution and movements under operating conditions in HT MEAs, which is a prerequisite for the understanding of HT-PEFC durability. In addition, this technique enables us to study in-situ diffusion across the PBI membrane during deuteration, helping to understand an important transport mechanism of HT-PEFC operation.

\section{References}

1. T. J. Schmidt, in Polymer Electrolyte Fuel Cell Durability, F. N. Büchi, M. Inaba, and T. J. Schmidt, Editors, p. 199, Springer, New York, 2009.

2. T. J. Schmidt, ECS Transactions, 1, 19 (2006).

3. J. Mader, L. Xiao, T. Schmidt, and B. Benicewicz, in Advances in Polymer Science: Fuel Cells II, G. Scherer, Editor, volume 216, p. 63, Springer Berlin Heidelberg, 2008.

4. T. J. Schmidt and J. Baurmeister, ECS Transactions, 3, 861 (2006).

5. D. C. Seel, B. C. Benicewicz, L. Xiao, and T. Schmidt, in Handbook of Fuel Cells: Advances in Electrocatalysis, Materials, Diagnostics and Durability, W. Vielstich, H. Yokogawa, and H. Gasteiger, Editors, volume 5, chapter 19, p. 300, John Wiley \& Sons, 2009.

6. C. Hartnig and T. J. Schmidt, Electrochimica Acta, 56, 4237 (2011)

7. H. R. Kunz, in Electrochemical Engineering - Mathematical Modelling; Electrochemical Society Proceedings, R. F. Savinell, J. Fenton, A. West, S. Scanlon, and J. Weidner, Editors, volume 99, p. 191, The Electrochemical Society: Pennington, NJ, USA, 1999, 1999.

8. A. Seya and I. Tadano, Kagaku Kogaku Ronbun., 27, 223 (2001).

9. K. Kwon, J. O. Park, D. Y. Yoo, and J. S. Yi, Electrochimica Acta, 54, 6570 (2009).

10. W. Maier, T. Arlt, C. Wannek, I. Manke, H. Riesemeier, P. Krüger, J. Scholta, W. Lehnert, J. Banhart, and D. Stolten, Electrochem. Commun., 12, 1436 (2010)

11. W. Maier, T. Arlt, K. Wippermann, C. Wannek, I. Manke, W. Lehnert, and D. Stolten, J. Electrochem. Soc., 159, F398 (2012).

12. S. H. Eberhardt, F. N. Büchi, and T. J. Schmidt, in Proceedings of the 4th European PEFC \& H2 Forum 2013, D. Jones, J. Rozière, S. Cavaliere, S. Subianto, N. Donzel, G. Taillades, F. Jaouen, and M. Taillades, Editors, p. A1103, The European Fuel Cell Forum, 2013.

13. P. Boillat, P. Oberholzer, B. C. Seyfang, A. Kaestner, R. Perego, G. G. Scherer, E. H. Lehmann, and A. Wokaun, J. Phys.: Condens. Matter, 23, 234108 (2011).

14. P. Oberholzer and P. Boillat, J. Phys. Chem. C, 117, 19945 (2013).

15. D. Kramer, J. Zhang, R. Shimoi, E. Lehmann, A. Wokaun, K. Shinohara, and G. G. Scherer, Electrochim. Acta, 50, 2603 (2005).

16. R. Satija, D. Jacobson, M. Arif, and S. Werner, J. Power Sources, 129, 238 (2004).

17. J. Owejan, T. Trabold, J. Gagliardo, D. Jacobson, R. Carter, D. Hussey, and M. Arif, J. Power Sources, 171, 626 (2007)

18. P. Boillat, D. Kramer, B. Seyfang, G. Frei, E. Lehmann, G. Scherer, A. Wokaun, Y. Ichikawa, Y. Tasaki, and K. Shinohara, Electrochem. Commun., 10, 546 (2008).

19. M. A. Hickner, N. P. Siegel, K. S. Chen, D. S. Hussey, D. L. Jacobson, and M. Arif, J. Electrochem. Soc., 155, B427 (2008).

20. I. Manke, C. Hartnig, N. Kardjilov, M. Messerschmidt, A. Hilger, M. Strobl, W. Lehnert, and J. Banhart, Appl. Phys. Lett., 92 (2008).

21. S. Kim and M. Mench, J. Electrochem. Soc., 156, B353 (2009).

22. H. Murakawa, D. Wada, K. Sugimoto, H. Asano, N. Takenaka, and R. Yasuda, Nucl. Instr. Meth. A, 651, 286 (2011).

23. P. Boillat, P. Oberholzer, A. Kaestner, R. Siegrist, E. H. Lehmann, G. G. Scherer, and A. Wokaun, J. Electrochem. Soc., 159, F210 (2012).

24. P. Oberholzer, P. Boillat, R. Siegrist, A. Kaestner, E. H. Lehmann, G. G. Scherer, and A. Wokaun, Electrochem. Commun., 20, 67 (2012).

25. E. Lehmann, G. Frei, G. Kühne, and P. Boillat, Nucl. Instr. Meth. A, 576, 389 (2007).

26. P. Boillat, G. Frei, E. H. Lehmann, G. G. Scherer, and A. Wokaun, Electrochem. Solid St., 13, B25 (2010).

27. A. Kaestner, S. Hartmann, G. Kuehne, G. Frei, C. Gruenzweig, L. Josic, F. Schmid, and E. H. Lehmann, Nucl. Instr. Meth. A, 659, 387 (2011).

28. D. I. MacDonald and J. R. Boyack, Journal of Chemical \& Engineering Data, 14, 380 (1969). 